\title{
Thrombophilia in hepatocellular carcinoma
}

\author{
Fayrouz O. Selim*, Taghrid M. Abdalla and Thoraya A. M. Hosny
}

\begin{abstract}
Background: Chronic liver disease and hepatocellular carcinoma (HCC) can cause a disturbance in the coagulation system. In this study, we aimed to assess the risk factors for venous thromboembolism either acquired or hereditary in patients with HCC.

Results: Serum levels of proteins C and S, AT activity, and lipoprotein (a) were significantly lower in both HCC and cirrhotic patients while homocysteine levels were significantly higher in HCC patients. The prevalence of activated protein $C$ resistance (APCR) and factor V Leiden (FVL) mutation was higher in HCC patients but with no significant differences between the studied groups. With multivariate analysis, prothrombin time, Fbg, protein $C$ and $S$ deficiency, increased lipoprotein (a), hyperhomocysteinemia, APCR, and FVL mutation were independent risk factors for thromboembolic complications in HCC patients.
\end{abstract}

Conclusions: Thrombophilic abnormalities are prevalent in HCC patients, and they have a substantial increased risk of venous thromboembolism.

Keywords: Hepatocellular carcinoma, Liver cirrhosis, Venous thromboembolism, Thrombophilia

\section{Background}

Hepatocellular carcinoma (HCC) is the most prevalent type of primary malignancy of the liver [1] and usually develops in patients with cirrhosis [2].

Since the liver has an important role in the synthesis and metabolism of coagulation factors, it regulates the blood clotting and anticoagulant system. Liver disease, such as liver cirrhosis, hepatitis, and HCC, can impair the liver's ability to produce clotting factors and anticoagulant proteins [3].

In addition, patients with advanced $\mathrm{HCC}$ have abnormal coagulation and fibrinolysis, which is related to tumor progression [4].

Chronic liver disease and HCC patients have a substantially increased risk of venous thromboembolism (VTE) as deep venous thrombosis (DVT) or pulmonary embolism (PE) [5].

In addition, portal vein thrombosis (PVT) is a common complication of HCC and non-malignant chronic liver disease. It shows worse liver functions, less tolerance to treatment, and worse prognosis [6].

Routine laboratory coagulation tests such as thrombin time (TT), prothrombin time (PT), activated partial

\footnotetext{
* Correspondence: feroo02012@hotmail.com

Faculty of Medicine, Zagazig University, Zagazig 44511, Sharqya governorate, Egypt
}

thromboplastin time (APTT), fibrinogen (Fbg), and Ddimer are commonly used to detect coagulation disorders [7].

Furthermore, hyperhomocysteinemia [8] and activated protein $\mathrm{C}$ resistance (APCR) have an association with venous thromboses in patients with cancer [9].

In addition, genetic defects as protein $\mathrm{C}$, protein $\mathrm{S}$, antithrombin (AT) deficiencies [10], and factor $\mathrm{V}$ Leiden (FVL) mutation [11], also, acquired coagulation disorders as increased levels of antiphospholipid antibodies have been discovered in patients with PVT [12].

We aimed to evaluate the presence of different coagulation defects either hereditary or acquired in cirrhotic patients and HCC and show their relationship with different thrombotic complications.

\section{Patients and methods}

Data were collected from cirrhotic patients with and without HCC, who were admitted to the HepatoGastroenterology Unit of Internal Medicine and Tropical Departments, Faculty of Medicine, Zagazig University, between March 2016 and April 2017. 


\section{Selection of cases}

In this cross-sectional study, a total number of 140 patients with liver cirrhosis and HCC and 45 healthy volunteers were included. The sample size is calculated by using Epi-Info version 7 . The study samples were systematically and randomly selected. The studied groups were matched for age and sex.

Our cases were divided into three groups as follows:

Control group: It included 45 apparently healthy volunteers, 23 males and 22 females, matched for age and gender.

Cirrhotic group: It included 70 cirrhotic patients without HCC, 40 males and 30 females. Liver cirrhosis was confirmed by biochemical and imaging findings. In addition, cirrhotic patients were classified according to Child-Pugh's score.

HCC group: It included 70 cirrhotic patients with HCC, 42 males and 28 females. HCC diagnosis was confirmed by serum AFP level $\geq 400 \mathrm{ng} / \mathrm{ml}$ with a hepatic space-occupying lesion, which is diagnosed by triphasic CT or MRI.

\section{Exclusion criteria}

We excluded the following:

1. Patients on procoagulant or anticoagulant therapy or have blood transfusions within 1 month of starting the study

2. Patients treated with anti-tumor treatment drugs or surgery

3. Patients with venous thromboembolism, pulmonary embolism, or disseminated intravascular coagulation, which can influence plasma coagulation levels within 1 month of study

4. Patients suffering from hematological malignancies, cancer, chronic inflammatory diseases, and apparent portal vein invasion by the tumor

5. Smokers and alcoholics

\section{Ethics approval and consent to participate}

Approvals for performing the study were obtained from Internal Medicine, Tropical Medicine, and Clinical Pathology Departments, Zagazig University Hospitals, after taking Institutional Review Board (IRB) approval. Written informed consent was taken from the patients or their relatives if patients were severely ill to participate in this study.

\section{Methods}

All participants subjected to a detailed history taking and clinical examination, and routine laboratory tests such as complete blood count, liver and kidney function tests, PT, PC, INR, APTT, TT, Fbg, blood sugar, and viral markers.
The following are the specific laboratory tests:

- The serum $\alpha$-fetoprotein levels were measured by Cobas electrochemiluminescence.

- Proteins C and S, antithrombin (AT) activity, and lipoprotein (a) were determined by ELISA.

- Activated protein $\mathrm{C}$ resistance (APCR) was measured by recording the activated partial thromboplastin time (APTT) in the absence and presence of APC.

- Plasma total homocysteine was measured by the IMX homocysteine assay.

- Molecular analysis of FVL mutation, using factor V gene mutation assay by genomic DNA isolation from EDTA blood and polymerase chain reaction.

The following are the investigations of thromboembolic complications:

- DVT was diagnosed by Doppler ultrasound [13].

- PE was confirmed by either computerized tomography $(\mathrm{CT})$ of the chest or ventilationperfusion scan [13].

- PVT was diagnosed by either Doppler ultrasound, CT, or MRI [14].

\section{Statistical analysis}

Variables were computerized and analyzed using SPSS version 19 (IBM Corporation, USA). Continuous variables were expressed as the mean \pm standard deviation (SD) for normally distributed data or median and interquartile range (IQR) for non-normally distributed data. MannWhitney $U$ test was used for non-parametric distribution. For comparisons of quantitative variables among the three groups, one-way ANOVA was used if the data was parametric, while the Kruskal-Wallis $H(\mathrm{KW})$ test was used if the data was non-parametric. Post-hoc Fisher's least significant difference (LSD) tests were used if significant differences were found between the three groups. Chi-square test $\left(\chi^{2}\right)$ was used for comparison between qualitative variables in different groups. $P$ value $>0.05$ indicates non-significant results. $P$ value $<0.05$ indicated significant results. Linear regression analysis served to assess the impact of thrombophilic parameters as predictors of thrombotic complications by both univariate and multivariate models.

\section{Results}

With regard to the etiologies of chronic liver disease or Child-Pugh's scores, there was no difference between HCC and cirrhotic patients. The mean values of MELD scores were significantly higher in HCC patients compared to cirrhotic patients. Serum AFP levels were statistically significantly increased in patients with HCC compared to 
other groups. The majority of cirrhotic and HCC patients were child $\mathrm{C}$ but without significant difference Table 1 .

Prothrombin time was significantly higher, while prothrombin concentration was significantly lower in HCC and cirrhotic patients compared to the control group.

TT, APTT and Fbg levels were significantly higher in HCC patients when compared with the control and cirrhotic groups. The serum levels of proteins $\mathrm{C}$ and $\mathrm{S}$, antithrombin, and lipoprotein (a) were significantly lower in both HCC and cirrhotic patients in comparison with controls. While in patients with HCC, serum homocysteine levels were significantly higher when compared to cirrhotic patients and controls Table 2.

The prevalence of APCR and FVL mutation was higher in HCC patients, but without significant differences between the groups.

Univariate analysis of various thrombophilic parameters in $\mathrm{HCC}$ showed that prothrombin time, Fbg, protein $\mathrm{C}$ and $\mathrm{S}$ deficiency, antithrombin deficiency, increased lipoprotein (a), hyperhomocysteinemia, APCR, and FVL mutation were significantly associated with the development of thrombotic complications in HCC patients. With further multivariate analysis, prothrombin time, Fbg, protein $\mathrm{C}$ and $\mathrm{S}$ deficiency, increased lipoprotein (a), hyperhomocysteinemia, APCR, and FVL mutation were independent risk factors for thromboembolic complications in HCC patients Table 3.
In-between 14 cases with thromboembolic complications in HCC, 8 of them (57.1\%) had at least 1 thrombophilic parameter. Seven out of 8 cases with thromboembolic complications had more than 1 risk factor of thrombosis. We had 8 cases with PVT (57.1\%), 4 cases with PE (28.5\%), and 2 cases with DVT (14.3\%) Table 4.

\section{Discussion}

VTE is a common complication in patients with malignant disease and can be the earliest signs of an underlying malignancy [15].

Hypercoagulable state occurs in the malignancy due to the ability of tumor cells to activate the coagulation system [16].

Within the liver, hepatocytes are involved in the synthesis of many coagulation factors that can be significantly decreased in patients with liver disease as HCC [17].

In addition, tumor cells produce several procoagulant factors and proinflammatory cytokines such as tissue factor (TF), tumor necrosis factor (TNF- $\alpha$ ), cancer procoagulant $(\mathrm{CP})$, vascular endothelial growth factor (VEGF), and interleukin-1 $\beta$ (IL-1 $\beta$ ) which support tumor metastasis and invasion [18].

TNF- $\alpha$, IL-1 $\beta$, and VEGF reduce activation of the protein $C$ system which is one of the endogenous anticoagulant systems [19].

Table 1 Demographic data and parameters of the studied groups

\begin{tabular}{|c|c|c|c|c|c|}
\hline Variables & Control group & Cirrhotic patients & HCC patients & $P$ value & Post hoc analysis \\
\hline Number & 45 & 70 & 70 & & \\
\hline Age & $54.8 \pm 7.19$ & $55 \pm 6.43$ & $56.87 \pm 6.26$ & $0.148^{*}$ & \\
\hline Sex (male/female) & $23 / 22$ & $40 / 30$ & $42 / 28$ & $x^{2} 0.6413$ & \\
\hline \multicolumn{6}{|l|}{ Etiology } \\
\hline Chronic hepatitis C & - & 45 & 48 & $x^{2} 0.8369$ & \\
\hline Chronic hepatitis B & - & 9 & 10 & & \\
\hline Non-alcoholic steatohepatitis & - & 8 & 5 & & \\
\hline Autoimmune hepatitis & - & 6 & 4 & & \\
\hline Cryptogenic & - & 2 & 3 & & \\
\hline \multicolumn{6}{|l|}{ Child-Pugh's score } \\
\hline Child A & - & 3 & 4 & $x^{2} 0.224$ & \\
\hline Child B & - & 20 & 29 & & \\
\hline Child C & - & 47 & 37 & & \\
\hline MELD score & - & $15(4-25)$ & $19(10-40)$ & $<0.001^{* *}$ & \\
\hline AFP $(\mathrm{ng} / \mathrm{ml})$ & $6(2-15)$ & $8(2-20)$ & $1700(500-3500)$ & $0.000^{* * *}$ & $\begin{array}{l}P 1=0.97 \\
P 2<0.001 \\
P 3<0.001\end{array}$ \\
\hline
\end{tabular}

Values are expressed as the mean \pm standard deviation (SD) while values of MELD score and AFP are given as the median and interquartile range (IQR) Significant difference $(P$ value $<0.05)$

$X^{2}$ chi-square test, $P 1$ control group vs cirrhotic patients, $P 2$ control group vs HCC patients, $P 3$ cirrhotic patients vs HCC patients, $M E L D$ model for end-stage liver disease, AFP a-fetoprotein

*ANOVA test

${ }^{* *}$ Mann-Whitney $U$ test

***Kruskal-Wallis test 
Table $\mathbf{2}$ Comparison of different thrombophilic parameters of the studied groups

\begin{tabular}{|c|c|c|c|c|c|}
\hline Variables & $\begin{array}{l}\text { Control group } \\
(N=45)\end{array}$ & $\begin{array}{l}\text { Cirrhotic patients } \\
(N=70)\end{array}$ & $\begin{array}{l}\text { HCC patients } \\
(N=70)\end{array}$ & $P$ value & $\begin{array}{l}\text { Post hoc } \\
\text { analysis }\end{array}$ \\
\hline PT (s) & $12.5 \pm 0.3$ & $22.3 \pm 5$ & $20.9 \pm 4.7$ & $0.0000^{*}$ & $\begin{array}{l}\mathrm{P} 1<0.001 \\
\mathrm{P} 2<0.001 \\
\mathrm{P} 3=0.14\end{array}$ \\
\hline Prothrombin conc.\% & $88.7 \pm 3.7$ & $36.6 \pm 17.6$ & $39.7 \pm 15$ & $0.0000^{*}$ & $\begin{array}{l}\mathrm{P} 1<0.001 \\
\mathrm{P} 2<0.001 \\
\mathrm{P} 3=0.40\end{array}$ \\
\hline$\Pi \mathrm{T}(\mathrm{s})$ & $18.7 \pm 1.41$ & $19.9 \pm 1.52$ & $33.22 \pm 13.62$ & $0.0000^{*}$ & $\begin{array}{l}\mathrm{P} 1=0.73 \\
\mathrm{P} 2<0.001 \\
\mathrm{P} 3<0.001\end{array}$ \\
\hline APTT (s) & $25.20 \pm 3.2$ & $27.53 \pm 4.45$ & $43.54 \pm 18.53$ & $0.0000^{*}$ & $\begin{array}{l}\mathrm{P} 1=0.55 \\
\mathrm{P} 2<0.001 \\
\mathrm{P} 3<0.001\end{array}$ \\
\hline $\mathrm{Fbg}(\mathrm{g} / \mathrm{l})$ & $2(0-10)$ & $2.5(0-15)$ & $10(2-25)$ & $0.0000^{* * *}$ & $\begin{array}{l}\mathrm{P} 1=0.99 \\
\mathrm{P} 2<0.001 \\
\mathrm{P} 3<0.001\end{array}$ \\
\hline Protein C (\%) & $99.8 \pm 26.3$ & $49.7 \pm 12.5$ & $54.5 \pm 15.3$ & $0.0000^{*}$ & $\begin{array}{l}\mathrm{P} 1<0.001 \\
\mathrm{P} 2<0.001 \\
\mathrm{P} 3=0.24\end{array}$ \\
\hline Protein S (\%) & $85.6 \pm 20.4$ & $61.8 \pm 10.2$ & $59.2 \pm 18.9$ & $0.0000^{*}$ & $\begin{array}{l}\mathrm{P} 1<0.001 \\
\mathrm{P} 2<0.001 \\
\mathrm{P} 3=0.62\end{array}$ \\
\hline Antithrombin activity (\%) & $88.1 \pm 10.4$ & $49.7 \pm 11.5$ & $52.5 \pm 9.7$ & $0.0000^{*}$ & $\begin{array}{l}\mathrm{P} 1<0.001 \\
\mathrm{P} 2<0.001 \\
\mathrm{P} 3=0.26\end{array}$ \\
\hline Lipoprotein (a) (mg/l) & $20(2-40)$ & $7(2-14)$ & $11(2-30)$ & $0.0000^{* * *}$ & $\begin{array}{l}\mathrm{P} 1<0.001 \\
\mathrm{P} 2<0.001 \\
\mathrm{P} 3=0.074\end{array}$ \\
\hline Homocysteine $(\mu \mathrm{mol} / \mathrm{l})$ & $12(5-18)$ & $15(7-29)$ & $26(10-45)$ & $0.0000^{* * *}$ & $\begin{array}{l}\mathrm{P} 1=0.13 \\
\mathrm{P} 2<0.001 \\
\mathrm{P} 3<0.001\end{array}$ \\
\hline $\operatorname{APCR}(N(\%))$ & $2(4.4 \%)$ & $6(8.6 \%)$ & $9(12.9 \%)$ & 0.3 & \\
\hline FVL mutation (N (\%)) & 1 (2.2\%) & $2(2.8 \%)$ & $4(5.7 \%)$ & 0.55 & \\
\hline
\end{tabular}

Values are expressed as the mean \pm standard deviation (SD) while values of Fbg, lipoprotein (a), and homocysteine are given as the median and interquartile range (IQR)

Significant difference $(P$ value $<0.05)$

$P 1$ control group vs cirrhotic patients, $P 2$ control group vs HCC patients, $P 3$ cirrhotic patients vs HCC patients, $P T$ prothrombin time, $\Pi T$ thrombin time, $A P T T$ activated partial thromboplastin time, Fbg fibrinogen, $A P C R$ activated protein $C$ resistance, FVL mutation factor $V$ Leiden (FVL) mutation

*ANOVA test

***Kruskal-Wallis test

In this study, there were significantly decreased levels of proteins $\mathrm{C}$ and $\mathrm{S}$, lipoprotein (a), and antithrombin in cirrhotic and HCC patients compared to controls. These results were expected because these proteins are synthesized in the liver, and their levels possibly decrease in patients with liver cirrhosis and HCC.

The liver is the main site for lipoprotein (a) synthesis and in chronic liver disease; the level of lipoprotein (a) decreased due to the decrease in its synthesis by damaged liver cells [20].

Hyperhomocysteinemia was also confirmed as a risk factor for recurrent VTE in many studies [21]. Patients with HCC had significantly higher levels of serum homocysteine compared to cirrhotic patients and controls in our study. These results were in agreement with Samonakis et al. [22].
Hyperhomocysteinemia in liver cirrhosis can be explained by impaired liver function and tissue damage that occur directly by increasing homocysteine cell leakage or indirectly by initiating cell repair [23].

Fibrinogen levels in HCC patients showed significantly higher levels than the control and cirrhotic groups. High fibrinogen levels may occur in our study due to their impaired elimination by the damaged liver cells that not only change the concentration of fibrinogen, but also make it structurally and functionally abnormal [24]. Hyperfibrinogenemia is associated with advanced HCC stage, poor prognosis and non-response to treatment [25].

Regarding genetic thrombotic risk factors, our study showed a high prevalence of APCR and FVL mutation in HCC patients but with no significant differences between 
Table 3 Univariate and multivariate analysis: comparison between thrombophilic parameters in HCC patients with and without thrombotic complications

\begin{tabular}{|c|c|c|c|c|c|c|}
\hline \multirow[t]{2}{*}{ Variables } & \multicolumn{3}{|c|}{ Univariate } & \multicolumn{3}{|c|}{ Multivariate } \\
\hline & ORs & $95 \% \mathrm{Cls}$ & $P$ value & ORs & $95 \% \mathrm{Cls}$ & $P$ value \\
\hline PT (s) & 13.12 & $4.64-18.12$ & 0.00 & 6.78 & $2.65-10.89$ & 0.00 \\
\hline Prothrombin conc.\% & 1.54 & $0.94-3.11$ & 0.18 & - & - & - \\
\hline$\Pi(\mathrm{s})$ & 1.92 & $0.63-3.81$ & 0.142 & - & - & - \\
\hline $\mathrm{Fbg}(\mathrm{g} / \mathrm{l})$ & 10.37 & $4.64-18.44$ & 0.00 & 3.97 & $2.17-12.34$ & 0.00 \\
\hline APTT (s) & 2.27 & $0.87-3.44$ & 0.085 & 2.33 & $0.71-7.75$ & 0.11 \\
\hline Protein C deficiency (\%) & 11.32 & $3.45-18.44$ & 0.00 & 4.81 & $3.11-10.82$ & 0.00 \\
\hline Protein S deficiency (\%) & 10.45 & $4.31-16.85$ & 0.00 & 4.32 & $2.98-11.42$ & 0.00 \\
\hline Antithrombin deficiency (\%) & 8.98 & $4.21-18.32$ & 0.00 & 2.71 & $0.64-1.74$ & 0.068 \\
\hline Increased lipoprotein (a) (mg/l) & 3.88 & $3.13-8.69$ & $<.0001$ & 2.784 & $2.23-5.36$ & 0.01 \\
\hline Hyperhomocysteinemia $(\mu \mathrm{mol} / \mathrm{l})$ & 6.24 & $3.41-19.24$ & 0.000 & 7.06 & $2.15-14.6$ & 0.000 \\
\hline APCR & 2.11 & $1.03-3.07$ & 0.03 & 2.53 & $1.12-4.71$ & 0.04 \\
\hline FVL mutation & 7.76 & $3.76-17.19$ & $<.0001$ & 6.12 & $2.25-15.41$ & 0.0003 \\
\hline
\end{tabular}

Significant difference $(P$ value $<0.05)$

ORs odds ratios, $C l$ confidence interval, $P T$ prothrombin time, $T$ thrombin time, $A P T T$ activated partial thromboplastin time, Fbg fibrinogen, $A P C R$ activated protein $C$ resistance, FVL mutation factor $V$ Leiden (FVL) mutation

the groups. This was in agreement with Samonakis et al. [22].

We found that, with univariate analysis, several factors such as prothrombin time, Fbg, protein $\mathrm{C}$ and $\mathrm{S}$ deficiency, antithrombin deficiency, increased lipoprotein

Table 4 Thrombophilic risk factors in HCC patients with thrombotic complications

\begin{tabular}{|c|c|c|}
\hline $\begin{array}{l}\text { No. of } \\
\text { cases }\end{array}$ & $\begin{array}{l}\text { Thromboembolic complications, } \\
\text { ( } N=14 \text { cases })\end{array}$ & Thrombotic risk factors \\
\hline 1 & Portal vein thrombosis & $\begin{array}{l}\text { Increased lipoprotein (a), } \\
\text { hyperhomocysteinemia }\end{array}$ \\
\hline 2 & Portal vein thrombosis & - \\
\hline 3 & Portal vein thrombosis & $\begin{array}{l}\text { Increased lipoprotein (a), } \\
\text { APCR }\end{array}$ \\
\hline 4 & Portal vein thrombosis & - \\
\hline 5 & Portal vein thrombosis & FVL mutation \\
\hline 6 & Portal vein thrombosis & - \\
\hline 7 & Portal vein thrombosis & $\begin{array}{l}\text { FVL mutation, APCR, } \\
\text { hyperhomocysteinemia }\end{array}$ \\
\hline 8 & Portal vein thrombosis & - \\
\hline 9 & Pulmonary embolism & - \\
\hline 10 & Pulmonary embolism & $\begin{array}{l}\text { Increased lipoprotein (a), } \\
\text { hyperhomocysteinemia }\end{array}$ \\
\hline 11 & Pulmonary embolism & $\begin{array}{l}\text { APCR, antithrombin } \\
\text { deficiency }\end{array}$ \\
\hline 12 & Pulmonary embolism & - \\
\hline 13 & Deep venous thrombosis & $\begin{array}{l}\text { Protein } C \text { deficiency, } \\
\text { protein } \mathrm{S} \text { deficiency }\end{array}$ \\
\hline 14 & Deep venous thrombosis & Prolonged PT, low Fbg \\
\hline
\end{tabular}

(a), hyperhomocysteinemia, APCR, and FVL mutation were significantly associated with the development of thrombotic complications in HCC patients. While with further multivariate analysis of the potentially important thrombotic parameters identified in univariate analysis, prothrombin time, $\mathrm{Fbg}$, protein $\mathrm{C}$ and $\mathrm{S}$ deficiency, increased lipoprotein (a), hyperhomocysteinemia, APCR, and FVL mutation showed independent significant association with thrombotic complications in HCC patient.

HCC carries an exclusive situation concerning cancerassociated thrombosis [26]. We found 14 cases with thromboembolic complications, $50 \%$ of them had more than 1 risk factor of thrombosis. PVT was a frequent complication of HCC.

PVT is common in HCC and characterized by an aggressive disease progression, worse liver functions, a higher chance of complications due to portal hypertension, and in addition, poorer tolerance to treatment [27].

Since cirrhosis and liver cell failure often precede the development of HCC, the frequency of DVT and PE in patients with cirrhosis was reported to be $0.5-1.0 \%$ [28]. PE and DVT are clearly a major cause of morbidity and mortality in HCC [29].

In our study, the etiology of venous thrombosis may be single or combined deficiencies of natural anticoagulant proteins (either acquired or genetic), and the majority of deficiencies were acquired.

Similar results were obtained by Ponziani et al. [30] and DeLeve et al. [31]. They suggested that patients with PVT commonly have acquired cause of anticoagulant protein deficiencies not hereditary genetic defects. 
However, a minority of PVT patients might have a hereditary anticoagulant protein deficiency [32].

The most important thrombotic risk factors in our HCC patients were hyperhomocysteinemia, increased lipoprotein (a), and APCR.

Therefore, we can suggest that thromboembolic complications in HCC are multifactorial, not only acquired but also genetic disorders.

There were some limitations to our study. First, all patients with HCC were included, irrespective of the etiology. Second, our sample size was relatively small, while larger studies were needed. Third, the rate of VTE might be underestimated if it occurs later.

The validity of our study depends on many issues. We excluded alcoholics and smokers as they are considered risk factors of VTE. In addition, cases with portal vein invasion by tumors were confirmed and excluded. We studied acquired coagulation parameters in addition to some genetic thrombotic risk factors.

\section{Conclusion}

In conclusion, thrombophilic abnormalities are prevalent in HCC patients, and they could be associated with different thromboembolic complications. The most important hypercoagulable risk factors in our HCC patients were hyperhomocysteinemia, increased lipoprotein (a), and APCR.

\section{Abbreviations}

APCR: Activated protein C resistance; APTT: Activated partial thromboplastin time; CP: Cancer procoagulant; CT: Computerized tomography; DVT: Deep venous thrombosis; Fbg: Fibrinogen; FVL: Factor $V$ Leiden;

HCC: Hepatocellular carcinoma; IL-1 $\beta$ : Interleukin-1 $\beta$; IRB: Institutional Review Board: PE: Pulmonary embolism; PT: Prothrombin time; PVT: Portal vein thrombosis; TF: Tissue factor; TNF-a: Tumor necrosis factor-alpha; TT: Thrombin time; VEGF: Vascular endothelial growth factor; VTE: Venous thromboembolism

\section{Acknowledgements}

The authors would like to acknowledge all the staff in the Faculty of Medicine, Zagazig University, for their assistance in conducting this study.

\section{Authors' contributions}

FO planned the original idea of the work. TM helped in the interpretation of the results, data collection, and in the drafting of the manuscript. TA carried out the preparation and experimental work. All authors read and approved the final manuscript.

\section{Funding}

The authors did not receive any funding from any person or organization or society.

\section{Availability of data and materials}

All data produced or analyzed during this study are included in this article.

\section{Ethics approval and consent to participate}

Approvals for performing the study were obtained from Internal Medicine, Tropical Medicine, and Clinical Pathology Departments, Zagazig University Hospitals, after taking Institutional Review Board (IRB) approval. Written informed consent was taken from the patients or their relatives if patients were severely ill to participate in this study.
Consent for publication

Provided with the submission of the article.

\section{Competing interests}

The authors declare that they have no competing interests.

Received: 10 July 2019 Accepted: 20 August 2019

Published online: 25 October 2019

\section{References}

1. Njei B, Rotman Y, Ditah I, Lim JK (2015) Emerging trends in hepatocellular carcinoma incidence and mortality. Hepatology 61:191-199

2. European Association For The Study Of The Liver (2012) EASL-EORTC clinical practice guidelines: management of hepatocellular carcinoma. J Hepatol 56:908-943

3. Shu YJ, Weng H, Bao RF, Wu XS, Ding Q, Cao Y et al (2014) Clinical and prognostic significance of preoperative plasma hyperfibrinogenemia in gallbladder cancer patients following surgical resection: a retrospective and in vitro study. BMC Cancer 14:566

4. Wang XP, Mao MJ, He ZL, Zhang L, Chi PD, Su JR, Dai SQ, Liu WL (2017) A retrospective discussion of the prognostic value of combining prothrombin time (PT) and fibrinogen (Fbg) in patients with hepatocellular carcinoma. J Cancer 8:2079

5. Søgaard KK, Horváth-Puhó E, Grønbæk H, Jepsen P, Vilstrup H, Sørensen HT (2009) Risk of venous thromboembolism in patients with liver disease: a nationwide population-based case-control study. Am J Gastroenterol 104:96

6. Jiang JF, Lao YC, Yuan BH, Yin J, Liu X, Chen L, Zhong JH (2017) Treatment of hepatocellular carcinoma with portal vein tumor thrombus: advances and challenges. Oncotarget 8:33911

7. Freitas $F$ (2015) What's new about sample quality in routine coagulation testing? Bioanálise 11:5-7

8. Gatt A, Makris M (2007) Hyperhomocysteinemia and venous thrombosis. Semin Hematol 44:70-76

9. Korte W (2018) Thrombosis and bleeding in cancer patients. In: The MASCC textbook of cancer supportive care and survivorship. Springer, Cham, pp 303-318

10. Zhou H, Xuan J, Lin X, Guo Y (2018) Recurrent esophagogastric variceal bleeding due to portal vein thrombosis caused by protein $S$ deficiency. Endoscopy International Open 6:E1283-E1288

11. Saugel B, Lee M, Feichtinger S, Hapfelmeier A, Schmid RM, Siveke JT (2015) Thrombophilic factor analysis in cirrhotic patients with portal vein thrombosis. J Thromb Thrombolysis 40:54-60

12. Ohe M, Mutsuki T, Goya T, Yamashita S, Satoh T, Kohjima M, Kato M (2016) Portal vein thrombosis repeatedly observed in a cirrhotic patient with antiphospholipid antibody syndrome. Fukuoka Igaku Zasshi 107:185-190

13. Dupras D, Bluhm J, Felty C, Hansen C, Johnson T, Lim K et al (2013) Venous thromboembolism diagnosis and treatment. Institute for Clinical Systems Improvement

14. Piscaglia F, Gianstefani A, Ravaioli M, Golfieri R, Cappelli A, Giampalma E et al (2010) Criteria for diagnosing benign portal vein thrombosis in the assessment of patients with cirrhosis and hepatocellular carcinoma for liver transplantation. Liver Transpl 16:658-667

15. Elyamany G, Alzahrani AM, Bukhary E. Cancer-associated thrombosis: an overview. Clinical Medicine Insights: Oncology 2014; 8: CMO-\$18991

16. Falanga A, Panova-Noeva M, Russo L (2009) Procoagulant mechanisms in tumour cells. Best Practice and Research Clinical haematology 22:49-60

17. Tripodi A, Mannucci PM (2011) The coagulopathy of chronic liver disease. N Engl J Med 365:147-156

18. Rak J, Milsom C, May L, Klement P, Yu J (2006) Tissue factor in cancer and angiogenesis: the molecular link between genetic tumor progression, tumor neovascularization, and cancer coagulopathy. Semin Thromb Hemost 32:54-70

19. Mackman N (2006) Role of tissue factor in hemostasis and thrombosis. Blood Cell Mol Dis 36:104-107

20. Jiang J, Zhang X, Wu C, Qin X, Luo G, Deng H et al (2008) Increased plasma apoM levels in the patients suffered from hepatocellular carcinoma and other chronic liver diseases. Lipids Health Dis 7:25

21. Hirmerová J (2013) Homocysteine and venous thromboembolism-is there any link? Cor et Vasa 55:e248-e258

22. Samonakis DN, Koutroubakis IE, Sfiridaki A, Malliaraki N, Antoniou P, Romanos J, Kouroumalis EA (2004) Hypercoagulable states in patients with hepatocellular carcinoma. Dig Dis Sci 49:854-858 
23. Ventura P, Rosa MC, Abbati G, Marchini S, Grandone E, Vergura P et al (2005) Hyperhomocysteinaemia in chronic liver diseases: role of disease stage, vitamin status and methylenetetrahydrofolate reductase genetics. Liver Int 25:49-56

24. Shao Z, Zhao Y, Feng L, Feng G, Zhang J, Zhang J. Association between plasma fibrinogen levels and mortality in acute-on-chronic hepatitis B liver failure. Disease Markers 2015

25. Zhang X, Long Q (2017) Elevated serum plasma fibrinogen is associated with advanced tumor stage and poor survival in hepatocellular carcinoma patients. Medicine 96

26. Ögren M, Bergqvist D, Björck M, Acosta S, Eriksson H, Sternby NH (2006) Portal vein thrombosis: prevalence, patient characteristics and lifetime risk: a population study based on 23796 consecutive autopsies. World J Gastroenterol 12:2115-2119

27. Chan SL, Chong CC, Chan AW, Poon DM, Chok KS (2016) Management of hepatocellular carcinoma with portal vein tumor thrombosis: review and update at 2016. World J Gastroenterol 22:7289-7300

28. Northup PG, McMahon MM, Ruhl AP, Altschuler SE, Volk-Bednarz A, Caldwell SH, Berg CL (2006) Coagulopathy does not fully protect hospitalized cirrhosis patients from peripheral venous thromboembolism. Am J Gastroenterol 101:1524-1528

29. Connolly GC, Chen R, Hyrien O, Mantry P, Bozorgzadeh A, Abt P, Khorana AA (2008) Incidence, risk factors and consequences of portal vein and systemic thromboses in hepatocellular carcinoma. Thromb Res 122:299-306

30. Ponziani FR, Zocco MA, Campanale C, Rinninella E, Tortora A, Di Maurizio L et al (2010) Portal vein thrombosis: insight into physiopathology, diagnosis, and treatment. World J Gastroenterol 16:143

31. DeLeve LD, Valla DC, Garcia-Tsao G (2009) Vascular disorders of the liver. Hepatology 49:1729-1764

32. Valla DC (2008) Thrombosis and anticoagulation in liver disease. Hepatology 47:1384-1393

\section{Publisher's Note}

Springer Nature remains neutral with regard to jurisdictional claims in published maps and institutional affiliations.

\section{Submit your manuscript to a SpringerOpen ${ }^{\circ}$ journal and benefit from:}

- Convenient online submission

- Rigorous peer review

- Open access: articles freely available online

- High visibility within the field

- Retaining the copyright to your article

Submit your next manuscript at $\boldsymbol{\nabla}$ springeropen.com 